\title{
RESECTION RECONSTRUCTION VERSUS AMPUTATION IN THE TREATMENT OF MALIGNANT TUMORS OF THE LIMBS
}

doi: 10.2478/rojost-2018-0071

Şt. Cristea, R. Popescu, Şt. Cuculici, M. Sava, A. Prundeanu, F. Groseanu, V. Georgeanu, R. Vișan

"Carol Davila" University of Medicine and Pharmacy, Bucharest, Romania; Orthopaedic Department, "Pantelimon" Emergency Hospital, Bucharest, Romania

Partial or complete excision of the tumoral segment with preservation of the limb extremity in the treatment of tumors is an alternative to amputation.

We present our cases with radical or wide resection and reconstruction with or without special prosthesis reconstruction.

We used an evaluation and prognosis score, which included surgical stage, site of tumor, size of tumor, surgical margin, functional mobility, and activity level after surgery.

Excision of the tumor with a wide margin, stable reconstruction and a good recovery is an alternative treatment to the amputation.

Keywords: resection, reconstruction, amputation, malignant tumors, limbs 